\title{
Selective and efficient electrochemical biosensing of ultrathin molybdenum disulfide sheets
}

\author{
Tharangattu N Narayanan ${ }^{1}$, Chiranjeevi S R Vusa and Subbiah Alwarappan ${ }^{1}$ \\ CSIR-Central Electrochemical Research Institute, Karaikudi 630006, Tamilnadu, India \\ E-mail: salwarap@gmail.com and tn_narayanan@yahoo.com
}

Received 4 February 2014, revised 4 June 2014

Accepted for publication 3 July 2014

Published 25 July 2014

\begin{abstract}
Atomically thin molybdenum disulfide $\left(\mathrm{MoS}_{2}\right)$ sheets were synthesized and isolated via solventassisted chemical exfoliation. The charge-dependent electrochemical activities of these $\mathrm{MoS}_{2}$ sheets were studied using positively charged hexamine ruthenium (III) chloride and negatively charged ferricyanide/ferrocyanide redox probes. Ultrathin $\mathrm{MoS}_{2}$ sheet-based electrodes were employed for the electrochemical detection of an important neurotransmitter, namely dopamine (DA), in the presence of ascorbic acid (AA). $\mathrm{MoS}_{2}$ electrodes were identified as being capable of distinguishing the coexistence of the DA and the AA with an excellent stability. Moreover, the enzymatic detection of the glucose was studied by immobilizing glucose oxidase on the $\mathrm{MoS}_{2}$. This study opens enzymatic and non-enzymatic electrochemical biosensing applications of atomic $\mathrm{MoS}_{2}$ sheets, which will supplement their established electronic applications.
\end{abstract}

S Online supplementary data available from stacks.iop.org/NANO/25/335702/mmedia

Keywords: atomic sheets, molybdenum disulfide, electrochemical biosensors, enzymatic detection

(Some figures may appear in colour only in the online journal)

\section{Introduction}

Recently, layered transition metal dichalcogenides (TMDs) have been extensively researched due to their structural similarities with graphene and their interesting physicochemical properties, along with their diverse exotic electronic properties [1-4]. Molybdenum disulfide $\left(\mathrm{MoS}_{2}\right)$ has been one such extensively studied and revisited material since its first report by Joesen et al in 1986 [5-8]. After the successful demonstration of $\mathrm{MoS}_{2}$-based field-effect transistors, and following many other interesting electronic and optoelectronic applications [9-11], various methods have evolved for the synthesis of good-quality $\mathrm{MoS}_{2}$ atomic layers. Liquid exfoliation of bulk crystals for getting atomic thin layers can be successfully optimized to produce large amounts of layered materials $[12,13]$. Layer thickness can be controlled and optimized by

\footnotetext{
1 (Authors contributed equally.)
}

sonication and centrifugation parameters. Large area one- to few-layered materials can be successfully obtained in bulk, leading to their various applications where the materials needed to be in bulk. Though high quality atomic 2D layers can be obtained using chemical vapor deposition (for example, $\mathrm{MoS}_{2}$ ), high temperature treatment with precarious gases and multistep laborsome transfer processes can be surpassed by an optimized liquid exfoliation process.

A layered structure, along with high specific surface areas of TMDs, can play an important role in sensing, catalysis and energy storage applications [14, 15]. In general, TMDs consist of hexagonal metal layers (M: for example, Mo in $\mathrm{MoS}_{2}$ ) sandwiched between two layers of chalcogen atoms (X: for example, $\mathrm{S}$ in $\mathrm{MoS}_{2}$ ) with a stoichiometry of $\mathrm{MX}_{2}$ (for example, $\mathrm{MoS}_{2}$ ). Figure 1(A) shows the layered structure of $\mathrm{MoS}_{2}$ where a Mo hexagonal layer is sandwiched between sulfur layers, with long bonding that shows the van der Waals interaction between each individual sandwiched layer 


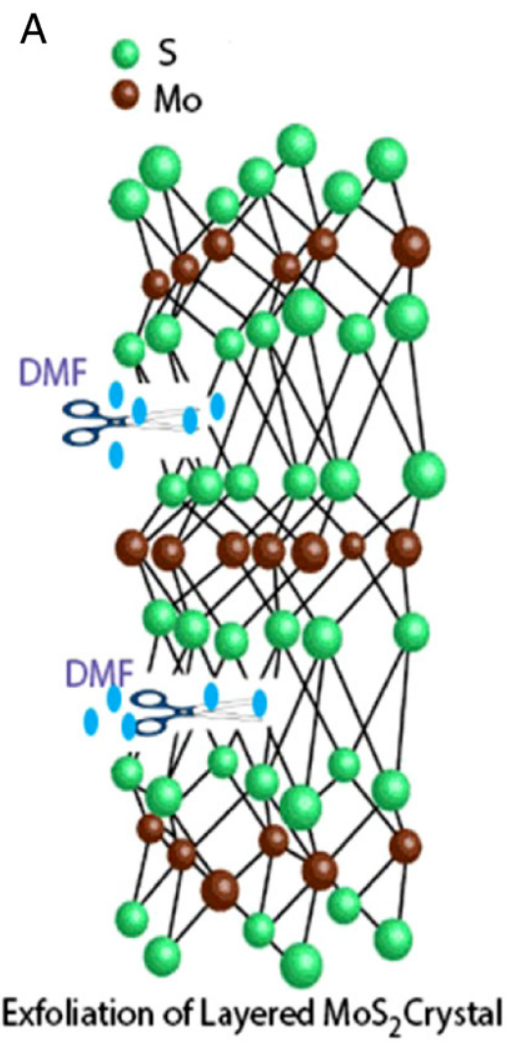

B

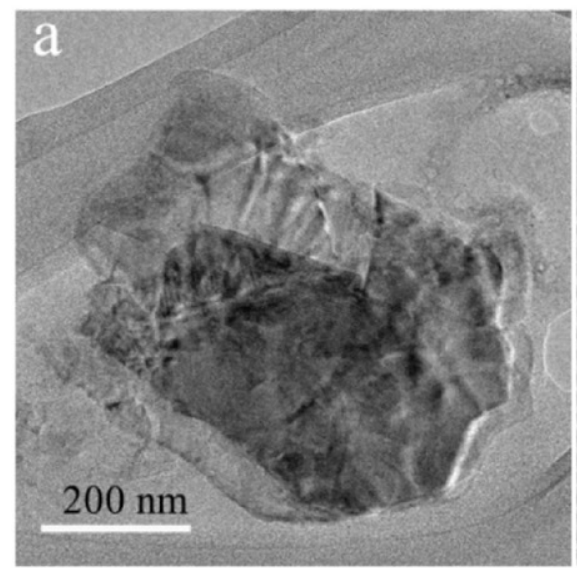

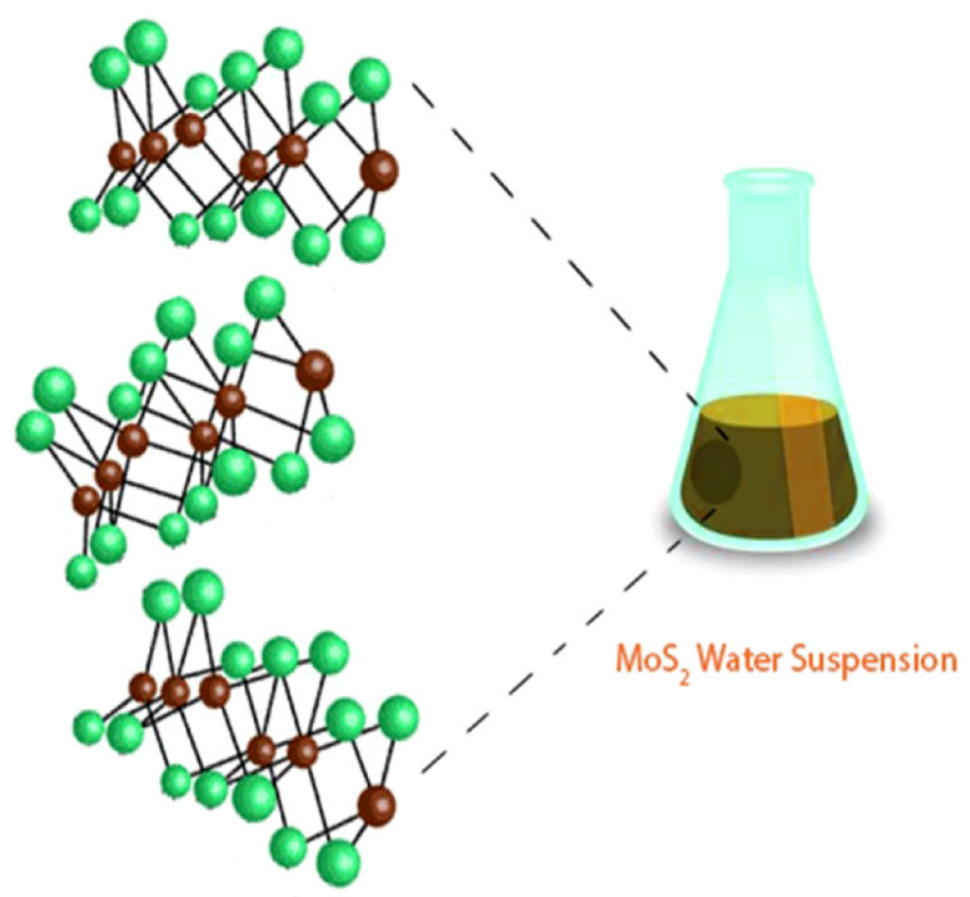

$\mathrm{MoS}_{2}$ Exfoliated Layers

C

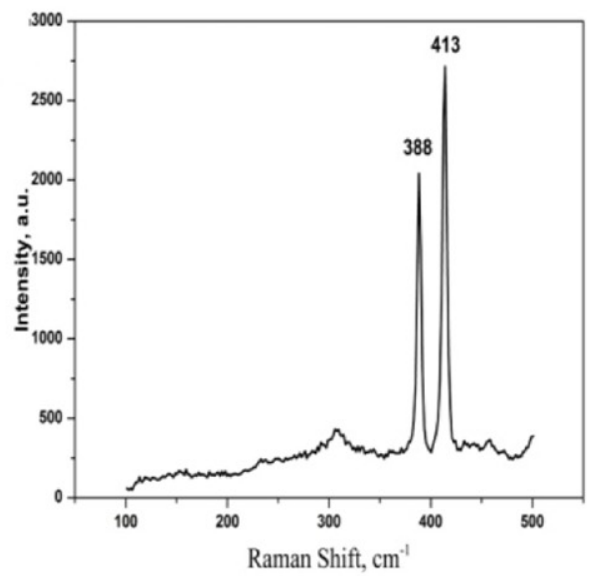

Figure 1. (A) Schematic of the exfoliation of the $\mathrm{MoS}_{2}$ (B) [a] TEM of $\mathrm{MoS}_{2}$, [b] HRTEM of MoS 2 , [c] Raman spectra of exfoliated MoS

(inter-planar distance $\sim 6.25 \AA$ ). The large surface area available in these layers, with their peculiar atomic distribution, can be utilized in selective biomolecular detection (up to fM levels) via electrochemical methods. It has been already shown both experimentally and computationally that the catalytic activity of $\mathrm{MoS}_{2}$ is due to the edges as opposed to the basal planes (due to the chemically inert nature of the basal planes). Kong et al [16] carried out the synthesis of vertically aligned $\mathrm{MoS}_{2}$ films and demonstrated their enhanced activities towards a hydrogen evolution reaction; however, this needs high temperature multistep synthesis routes. The synthesis of ultrathin layers in a solution and their random self-assembly on a substrate can also expose a large number of edge planes to the surface; moreover, this process can be performed at room temperature with an open room for large area device fabrication.

Dopamine (DA) is considered to be a very important neurotransmitter because it plays a key role in the motor and cognitive functions in humans and animals [17]. Also, DA modulates several aspects of brain circuitry [18]. In humans, the depletion of dopamine causes Parkinson's disease $[17,19,20]$. On the other hand, an abnormally high dopaminergic neurotransmission is associated with schizophrenia and Tourette syndrome [21, 22]. As a result, there is a significant interest amongst researchers in developing novel materials and appropriate methods to detect dopamine with high sensitivity. More recently, electrochemical methods are widely preferred to detect these neurotransmitters because 
many of these neurotransmitters are electroactive. Further, miniaturization of the electrodes will conveniently allow electroanalysis inside of the neural cells and in other intracellular region of interest $[23,24]$. However, in the neuronal region, DA always coexists with its common interferent, AA, and both of them undergo oxidation at a similar potential under physiological conditions ( $\mathrm{pH} 6.9-\mathrm{pH} 7.5)$ [25, 26]. In addition, the concentration of AA is always higher than that of DA; thereby, reliable measurement and quantification of DA is very difficult [27]. In order to overcome this issue, there has been considerable interest amongst researchers regarding the development of an alternate electrode or a material/modified electrodes for the selective detection of DA in the presence of elevated amounts of AA [27-31]. However, all of these modified electrodes are associated with one or more of the following drawbacks: electrode fouling, nonuniform thickness and slow response time [32, 33].

In the past decade, there has been significant interest amongst researchers regarding the development of glucose sensors to identify 'diabetics mellitus' at an early stage, as this disease is considered to be a major worldwide health risk [34]. The major causes for this disorder are insulin deficiency and hyperglycemia [34]. Glucose concentrations higher or lower than the usual level ( 4.5 to $6.5 \mathrm{mM}$ ) cause this disorder [34]. Other complications of diabetes include renal problems, weight loss, heart problems and permanent blindness. In order to overcome these problems, it is very essential to control blood glucose levels. Therefore, it has become very essential to strictly monitor blood glucose levels regularly. Several enzymatic and non-enzymatic electrochemical glucose sensors have been reported in the literature [34-37]. However, all of these reported glucose biosensors suffer from poor stability, enzyme leaching and slow electron shuttling properties. So, there is an urgent need to develop electrochemical biosensors based on 2D nanomaterials with a high surface to volume ratio. Such 2D nanomaterials are profound, with numerous functional groups and edge plane sites that can be modified with required enzymes for highly sensitive and rapid electrochemical detection. To the best of our knowledge, only 2D nanomaterials, such as graphene-oxide, graphene and reduced $\mathrm{MoS}_{2}\left(\mathrm{rMoS}_{2}\right)$, have been employed as biosensing platforms [38-40], whereas $\mathrm{MoS}_{2}$ have not been employed as an electrode material for the electrochemical biosensing of neurotransmitters or glucose. Therefore, in this work, we propose $\mathrm{MoS}_{2}$ as an alternate electrode material for efficient, stable and rapid enzymatic and non-enzymatic electrochemical biosensing applications for the first time.

\section{Experimental methods}

\subsection{Exfoliation of $\mathrm{MoS}_{2}$ atomic layers}

$\mathrm{MoS}_{2}$ atomic layers were prepared by a liquid exfoliation method using $\mathrm{MoS}_{2}$ micron-sized powders (Bay Carbon, Inc.) as a starting material. Dimethyl formamide (DMF) was used as the exfoliation medium (room temperature surface tension $\sim 37 \mathrm{mN} \mathrm{m}^{-1}$ ). The pristine powder was sonicated for $3 \mathrm{~h}$, and the resultant solution was centrifuged at a high rate of $3000 \mathrm{rpm}$. The resultant supernatant was collected, filtered and dried. TEM (FEI Tecnai $20 \mathrm{G}^{2}$ ) and HRTEM (JEM$2100 \mathrm{~F}$ ) measurements were carried out to understand the morphology, thickness and crystallinity of the exfoliated sheets. Raman spectroscopy was conducted using a Renishaw Laser Raman Microscope (514.5 nm).

\section{2. $\mathrm{MoS}_{2}$ electrode fabrication}

$1 \mathrm{mg}$ of $\mathrm{MoS}_{2}$ was dissolved in $1 \mathrm{~mL}$ of acetone and ultrasonicated for about $2 \mathrm{~h}$ at room temperature. About $5 \mu \mathrm{L}$ of the resulting solution was drop-casted onto the polished glassy carbon electrode and allowed to dry for $1 \mathrm{~h}$ at room temperature. After $1 \mathrm{~h}$, the electrode was gently rinsed with DI water thrice to remove impurities (if any were present on its surface). The resulting electrode was then employed for all of the electrochemical experiments.

\subsection{Electrochemical characterizations}

Hexammine ruthenium (III) chloride, potassium hexacyanoferrate (III), potassium hexacyanoferrate (IV), sodium phosphate (dibasic salt), sodium chloride, trisodium citrate and bovine serum albumin were all purchased from Sigma-Aldrich (St. Louis, MO) and used without any further purification. Glassy carbon electrodes, $\mathrm{Ag} / \mathrm{AgCl}(3.0 \mathrm{M} \mathrm{KCl})$ reference electrodes and platinum wire counter electrodes were all purchased from $\mathrm{CH}$ Instruments (Austin, Texas, USA).

\subsection{Calculation of the electrode surface area}

The electrochemical active surface area of the bare GC and the $\mathrm{MoS}_{2}$ electrode was calculated based on the Randles-Sevick equation:

$$
I_{\mathrm{pa}}=\left(2.69 \times 10^{5}\right) n^{3 / 2} A D^{1 / 2} v^{1 / 2} C_{\mathrm{ox}} .
$$

In the above equation, $v$ represents the potential scan rate, and $C_{\mathrm{ox}}$ is the bulk concentration of an oxidant. The electrochemical surface area $(A)$ was estimated from the anodic peak current $\left(I_{\mathrm{pa}}\right)$, obtained in the linear scan voltammogram of $5.0 \mathrm{mM}\left[\mathrm{Fe}(\mathrm{CN})_{6}\right]^{4-}$ in $1.0 \mathrm{M} \mathrm{KCl}$ as a supporting electrolyte. Five determinations of this parameter at a scan rate of $50 \mathrm{mVs}^{-1}$, using a $D$ value of $6.5 \times 10^{-6} \mathrm{~cm}^{2} \mathrm{~s}^{-1}$ at $20^{\circ} \mathrm{C}$ [41], gave a mean electrochemically active area of $(0.072 \pm 0.002)$ $\mathrm{cm}^{2}$ and $(0.0880 \pm 0.003) \mathrm{cm}^{2}$ (where the error represents the standard deviation), which corresponds to the bare GC and $\mathrm{MoS}_{2}$ modified electrodes, respectively.

\section{Results and discussion}

Solvent-assisted liquid exfoliation has been optimized to get one- to few-layered $\mathrm{MoS}_{2}$ sheets. Dimethyl formamide (DMF) is used as the solvent medium for exfoliation. Solventassisted exfoliation has been well studied in the literature for the obtainment of layered materials [12]. Figure 1(A) depicts the mechanism of the formation of atomic layers from bulk 

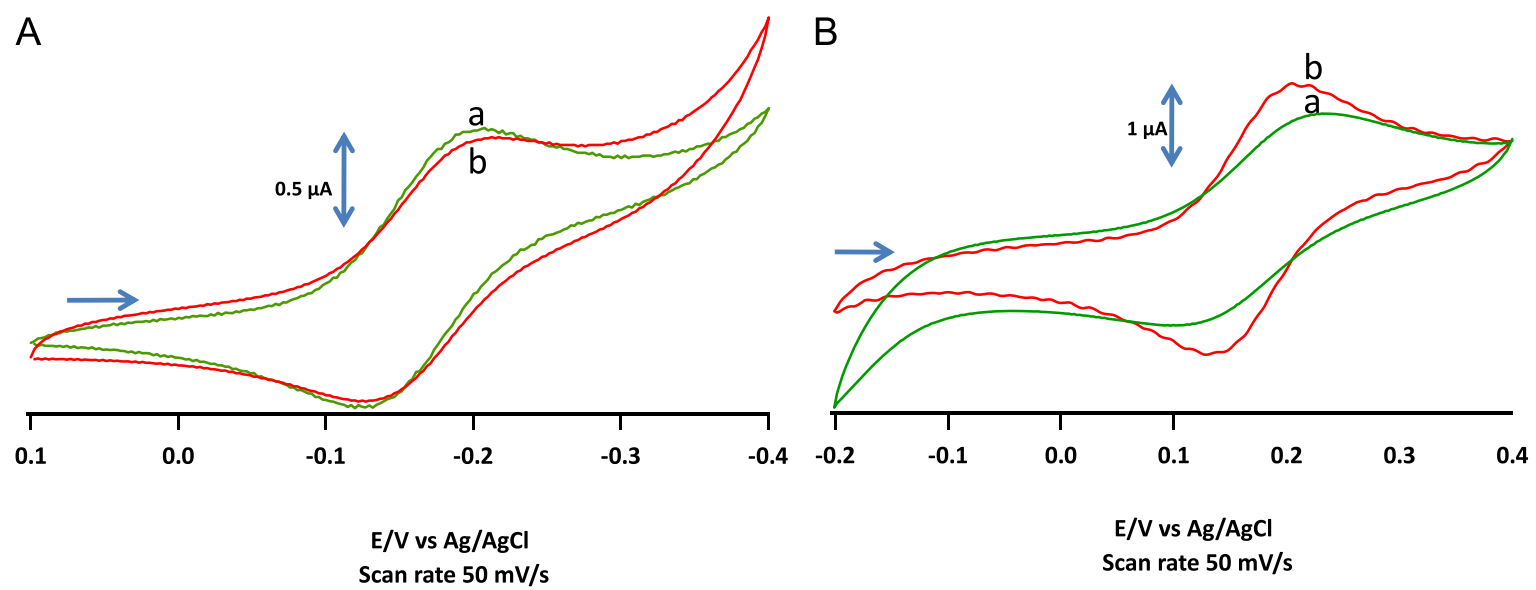

Figure 2. Cyclic voltammogram of (A) $0.1 \mathrm{mM}\left[\mathrm{Ru}\left(\mathrm{NH}_{3}\right)_{6}\right]^{3+/ 2+} / 1.0 \mathrm{M} \mathrm{KCl}$, (B) $0.1 \mathrm{mM}\left[\mathrm{Fe}(\mathrm{CN})_{6}\right]^{3-/ 4-} / 1.0 \mathrm{M} \mathrm{KCl}$ at (a) the $\mathrm{MoS}_{2}$ electrode, (b) the GC electrode.

crystals using DMF-assisted exfoliation. The transmission electron microscope (TEM) and high-resolution TEM (HRTEM), shown in figures $1 \mathrm{~B}(\mathrm{a})$ and (b), indicate the formation of crystalline few-layered (2-3 atomic layers) $\mathrm{MoS}_{2}$ sheets. The selective area electron diffraction shows (figure $1 \mathrm{~B}(\mathrm{~b})$ inset) the hexagonal structure, and the dotted hexagonal pattern indicates that the layer thickness is low enough (in this case, 1-3 layers). The Raman measurement on the exfoliated powder shows Raman shifts at 388 and $413 \mathrm{~cm}^{-1}$, indicating $\mathrm{E}_{2 \mathrm{~g}}^{1}$ and $\mathrm{A}_{1 \mathrm{~g}}$ modes of $2 \mathrm{H}-\mathrm{MoS}_{2}$, respectively (figure $1 \mathrm{~B}(\mathrm{c})$ ).

The charge transfer properties of $\mathrm{MoS}_{2}$ has been studied by performing cyclic voltammetry of $0.1 \mathrm{mM}\left[\mathrm{Ru}\left(\mathrm{NH}_{3}\right)_{6}\right]^{3+/ 2+}$ in a $1.0 \mathrm{M} \mathrm{KCl}$ electrolyte. Figures $2 \mathrm{~A}(\mathrm{a})$ and $2 \mathrm{~A}(\mathrm{~b})$ represent the cyclic voltammograms obtained at the $\mathrm{MoS}_{2}$ electrode (glassy carbon electrode modified with $\mathrm{MoS}_{2}$ ) and on the bare glassy carbon electrode, respectively. It is observed that the $\mathrm{MoS}_{2}$ electrode exhibited a $\Delta \mathrm{E}_{\mathrm{p}}$ value of $70 \mathrm{mV} \pm 6 \mathrm{mV}(\mathrm{N}=5$ electrodes). On the other hand, the glassy carbon electrode exhibited a $\Delta \mathrm{E}_{\mathrm{p}}$ value of $50 \mathrm{mV} \pm 2 \mathrm{mV}$ ( $\mathrm{N}=5$ electrodes). However, there is no significant change in their current density. From this observation, it is evident that both the $\mathrm{MoS}_{2}$ electrode and the glassy carbon electrode have similar effects on the electron transfer property of outer-sphere redox systems such as $\left[\mathrm{Ru}\left(\mathrm{NH}_{3}\right)_{6}\right]^{3+}$. Cyclic voltammetry of another redox probe, say $0.1 \mathrm{mM}\left[\mathrm{Fe}(\mathrm{CN})_{6}\right]^{3-/ 4-}-$, which is an inner sphereredox probe, is conducted to further unveil the charge transfer mechanism (figures $2 \mathrm{~B}(\mathrm{a})$ and $2 \mathrm{~B}(\mathrm{~b})$ ). McCreery et al demonstrated that the voltammetry of $\left[\mathrm{Fe}(\mathrm{CN})_{6}\right]^{3-/ 4-}$ is sensitive to the surface cleanliness and also to the surface chemistry of the hydrogen and oxygen functionalities present in carbonbased electrodes [42]. Moreover, the electron transfer reaction that involves $\left[\mathrm{Fe}(\mathrm{CN})_{6}\right]^{3-/ 4}$ proceeds through an inner-sphere pathway, with the electrode kinetics sensitive to the surface chemistry and microstructure and the density of the electronic states near the Fermi potential. The voltammogram obtained using the $\mathrm{MoS}_{2}$ electrode depicted a redox peak with a $\Delta \mathrm{E}_{\mathrm{p}}$ value of $75 \mathrm{mV} \pm 8 \mathrm{mV}$ ( $\mathrm{N}=5$ electrodes). On the other hand, the glassy carbon electrode exhibited a $\Delta \mathrm{E}_{\mathrm{p}}$ value of
$54 \mathrm{mV} \pm 3 \mathrm{mV}$ ( $\mathrm{N}=5$ electrodes). Upon comparing the current density, it is evident that the $\mathrm{MoS}_{2}$ electrode depicted a lower magnitude of peak current density than the bare glassy carbon electrodes. This result demonstrated that the $\mathrm{MoS}_{2}$ contains excess surface negative charges, which thereby repelled the negatively charged $\left[\mathrm{Fe}(\mathrm{CN})_{6}\right]^{3-/ 4-}$ away from the electrode surface and resulted in a diminished peak current density. The presence of a surface negative charge on the $\mathrm{MoS}_{2}$ surface at $\mathrm{pH} 7.0$ is further confirmed from the zeta potential measurement $(-10 \mathrm{mV})$. Further, the $\mathrm{MoS}_{2}$ showed a negative zeta potential value in the $\mathrm{pH} 4$ to 8 range, which is in excellent agreement with the earlier reports [43]. Hence, the cyclic voltammetry studies on these standard redox probes reflects the fact that $\mathrm{MoS}_{2}$ can be effectively employed for electroanalysis; this has been further studied in the following sections. Figure $3 \mathrm{~A}$ (a) represents the cyclic voltammogram obtained using $1.0 \mathrm{mM} \mathrm{DA} / \mathrm{pH} 7.4$ (PBS) at the $\mathrm{MoS}_{2}$ electrode. For comparison, the same set of experiments have been performed at the glassy carbon electrode [figure 3A(b)]. From the results, it is evident that the $\mathrm{MoS}_{2}$ electrode exhibits an oxidation peak centered at $140 \mathrm{mV} \pm 14 \mathrm{mV}(\mathrm{N}=5)$, and the bare electrode exhibits an oxidation peak centered at $300 \mathrm{mV} \pm 12 \mathrm{mV}$ $(\mathrm{N}=5)$, which corresponds to the oxidation of the DA. Upon comparison, it is evident that the oxidation of the DA occurs at a less positive potential in the case of the $\mathrm{MoS}_{2}$ electrode, which confirms its excellent electrochemical biosensing property toward the chosen analyte DA as opposed to the glassy carbon electrode. Cyclic voltammetry of $1.0 \mathrm{mM} \mathrm{AA} / \mathrm{pH} 7.4$ PBS with a $\mathrm{MoS}_{2}$ electrode is conducted in a similar fashion. In this case, we noticed that the $\mathrm{MoS}_{2}$ electrode exhibited an oxidation peak centered at $520 \mathrm{mV} \pm 13 \mathrm{mV}(\mathrm{N}=5)$, while the glassy carbon electrode exhibited an oxidation peak centered at $400 \mathrm{mV} \pm 19 \mathrm{mV}(\mathrm{N}=5)$, which corresponds to the oxidation of the AA. Moreover, the $\mathrm{MoS}_{2}$ electrode exhibited a lower peak current density than that of the glassy carbon electrode. This observed behavior at the $\mathrm{MoS}_{2}$ electrode can be attributed to the repulsion experienced by the negatively charged AA molecules from the surface's negative charge, which was spread over the $\mathrm{MoS}_{2}$ nanosheets. A common problem 

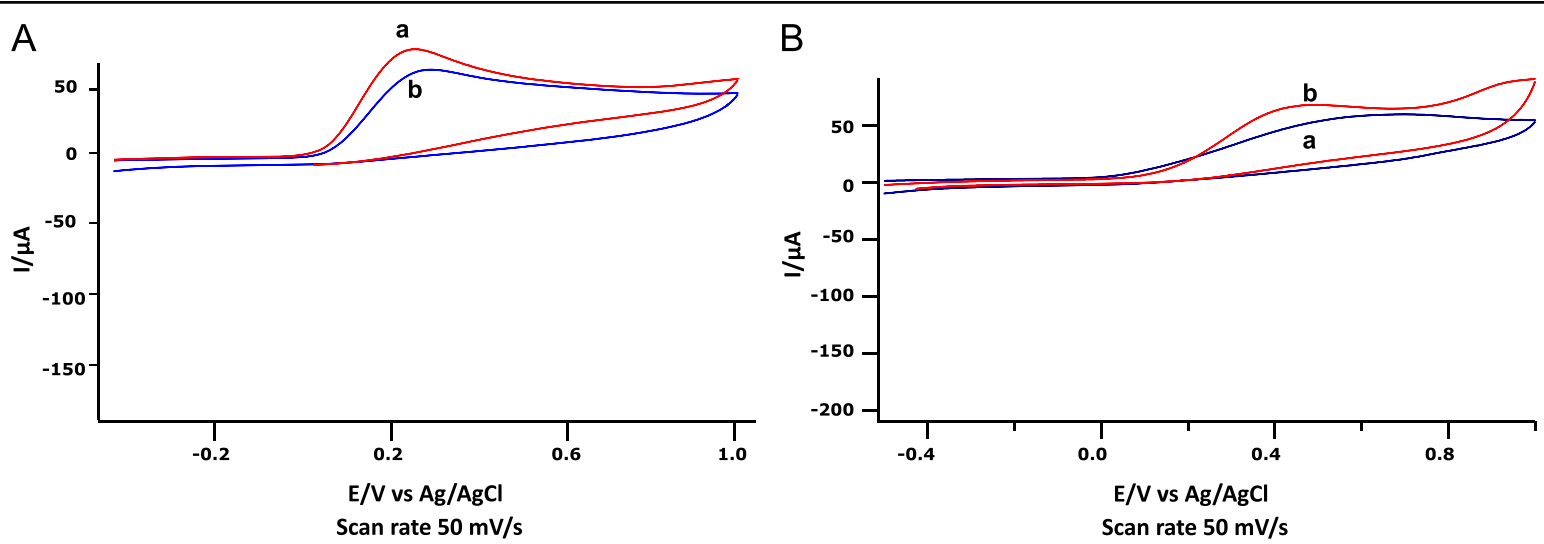

Figure 3. Cyclic voltammogram of (A) $1 \mathrm{mM} \mathrm{DA}$, (B) $1 \mathrm{mM} \mathrm{AA}$ at (a) the $\mathrm{MoS}_{2}$ electrode, (b) the GC electrode.

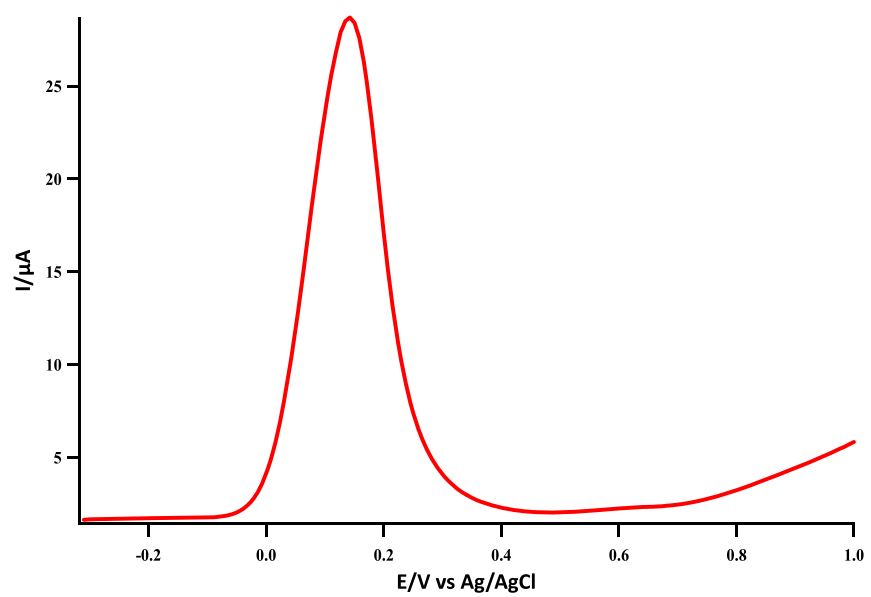

Figure 4. Differential pulse voltammogram of $0.1 \mathrm{mM}$ DA in the presence of $10 \mathrm{mM} \mathrm{AA}$ at the $\mathrm{MoS}_{2}$ electrode.

encountered during the detection of dopamine at the neutral $\mathrm{pH}$ is the interference of AA. In order to check the usefulness of $\mathrm{MoS}_{2}$ electrodes towards the selective detection of DA in the presence of excess AA, differential pulse voltammetry was performed at this electrode in $0.1 \mathrm{mM} \mathrm{DA}$ and $10 \mathrm{mM}$ AA in $\mathrm{pH} 7.4$ PBS (figure 4). Herein, we noticed the appearance of only one peak centered at $140 \pm 6 \mathrm{mV}(\mathrm{N}=5)$ that corresponds to the oxidation of the DA, and there is no peak that corresponds to the oxidation of the AA. From this particular observation, it is clear that the presence of AA has no effect on the oxidation of the DA, and we confirm that the $\mathrm{MoS}_{2}$ electrode has the ability to eliminate the signal arising from the AA when it co-exists the DA. This is due to the electrostatic repulsion experienced by the AA molecules by negatively charged $\mathrm{MoS}_{2}$ sheets. However, the DA is positively charged at $\mathrm{pH} 7.4$; thereby, it can be favorably detected at these negatively charged $\mathrm{MoS}_{2}$ surfaces. From this observation, it is also clear that the ultrathin $\mathrm{MoS}_{2}$ electrodes require no further modification steps to eliminate the interference caused by other coexisting negatively charged molecules, which is often a very difficult task with other bare electrodes. From all the abovementioned results, it is evident that $\mathrm{MoS}_{2}$ is a potential platform for sensitive electrochemical biosensing applications.

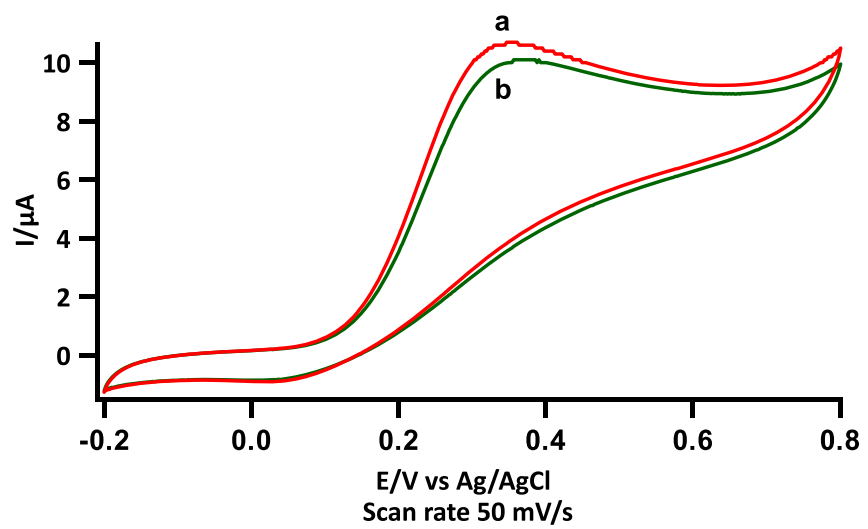

Figure 5. Cyclic voltammogram of $1.0 \mathrm{mM}$ DA at the $\mathrm{MoS}_{2}$ electrode: (a) 5th cycle, (ii) 50th cycle.

Following this, the stability of the ultrathin $\mathrm{MoS}_{2}$ sheets during the electroanalysis was also evaluated by performing fifteen consecutive voltammetric cycles in $1.0 \mathrm{mM} \mathrm{DA} /$ $\mathrm{pH}$ 7.4 PBS. The results indicate that the $\mathrm{MoS}_{2}$ electrode exhibits only a $5 \% \pm 1.5 \%(\mathrm{~N}=5)$ decrease in its peak current density after fifty cycles (figure 5), which indicates the excellent stability of the electrode during prolonged electrochemical analysis. Further, a plot of the current density against the square root of the scan rate displayed a straight line that indicates that the oxidation of DA at the $\mathrm{MoS}_{2}$ electrode is diffusion-controlled (supplementary figure 1(s), available from stacks.iop.org/NANO/25/335702/mmedia).

Apart from the non-enzymatic detection, the enzymatic detection of biomolecules is also important in modern clinical diagnoses. In this work, we have carried out the enzymatic detection of glucose at the $\mathrm{MoS}_{2}$ electrode. Initially, the binding of the enzyme, glucose oxidase, to the electrode was confirmed from the transmission electron micrographs (figure 6). As evident from the TEM image, it is clear that the amorphous glucose oxidase covered the crystalline atomic sheets. In order to confirm the presence of crystalline $\mathrm{MoS}_{2}$, SAED has been taken, as shown in the set.

Following this, to assess the performance of $\mathrm{MoS}_{2}$ towards glucose detection, cyclic voltammetry of $0.1 \mathrm{M} B-\mathrm{D}-$ glucose in $\mathrm{pH}$ 7.4 PBS is performed with the $\mathrm{MoS}_{2}$ electrode 


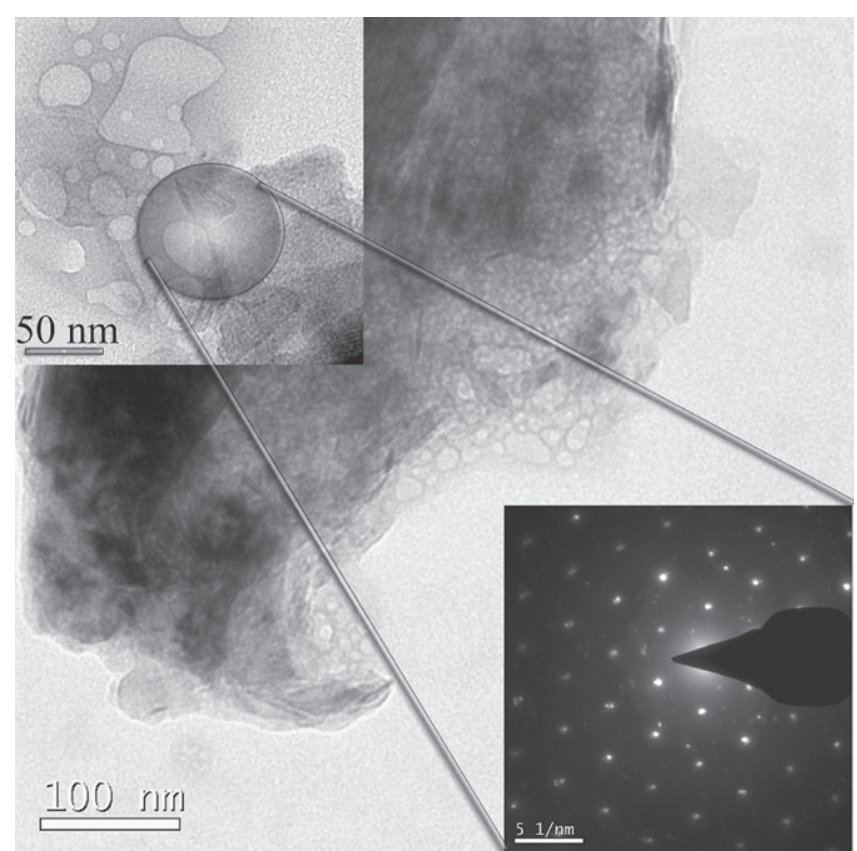

Figure 6. Transmission electron micrographs of $\mathrm{MoS}_{2}$ immobilized with Gox.

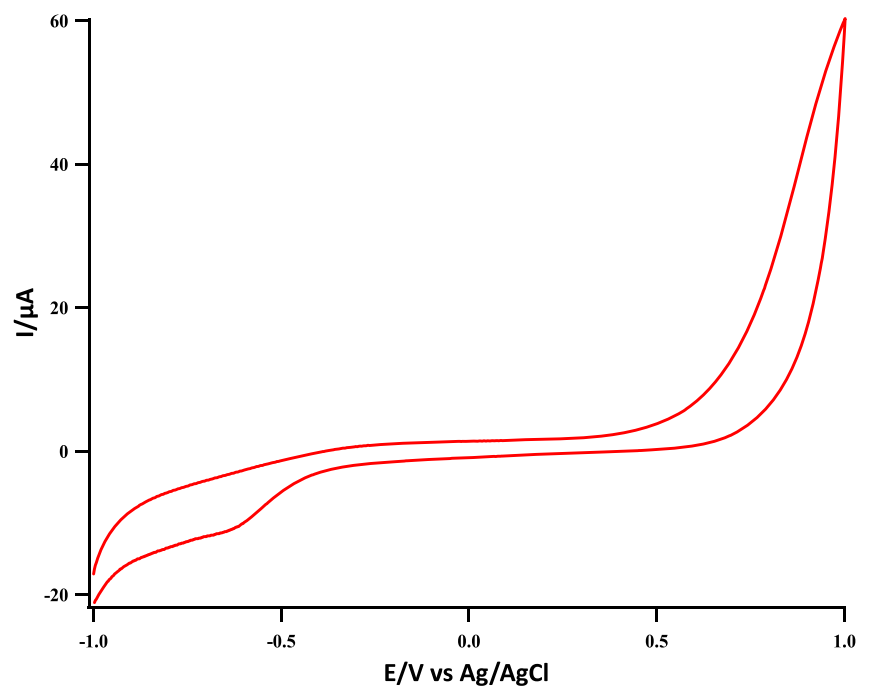

Figure 7. Cyclic voltammogram of $1.0 \mathrm{mM}$ glucose at the $\mathrm{MoS}_{2}$ electrode immobilized with Gox.

immobilized with the enzyme glucose oxidase; the corresponding voltammogram is shown in figure 7. As a control, similar experiments were conducted with a glucose oxidase modified glassy carbon electrode and a bare $\mathrm{MoS}_{2}$ electrode without enzyme immobilization (both controls not shown). In either case, there is no representative redox peaks, as is observed with the enzyme-immobilized $\mathrm{MoS}_{2}$ electrode. The peak centered at $-0.6 \mathrm{~V}$ noticed in figure 7 , reveals that the enzyme-immobilized $\mathrm{MoS}_{2}$ electrode can be a potential candidate for enzymatic biosensing than the other two electrodes. The observed behavior can be explained as follows: in $\mathrm{MoS}_{2}$, one positively charged molybdenum plane is sandwiched between two negatively charged sulfur planes. Every single molybdenum atom is linked to six sulfur atoms in a trigonalprismatic fashion [44]. As a result, the entire $\mathrm{MoS}_{2}$ surface is in a favorable geometry to accommodate the guest glucose oxidase through physical entrapment [44]. Further, it is established from the growing demand for $\mathrm{MoS}_{2}$ surfaces for scanning probe microscopy studies that organic molecules can bind with $\mathrm{MoS}_{2}$ surfaces, since their binding properties are greater than highly oriented pyrolytic graphite or mica [43]. Therefore, it is possible that glucose oxidase might have a higher affinity towards the $\mathrm{MoS}_{2}$ electrode, which gives further leverage for an elevated electron transfer between the $\mathrm{MoS}_{2}$ and the glucose oxidase. Further, it is also expected that the basal plane of the $\mathrm{MoS}_{2}$ interacts with the unsaturated carbon rings present in the glucose oxidase by means of van der Waals interaction, which thereby stabilizes the enzyme on the electrode surface. Such stabilization is expected to bring the immobilized Flavin Adenine Dinucleotide (FAD) center of the enzyme glucose oxidase to a closer proximity to the electrode surface and to facilitate the direct electron transfer for the enhanced electrochemical detection of glucose under physiological conditions.

\section{Conclusions}

Herein, we demonstrated the electrochemical enzymatic and non-enzymatic biosensing applications of ultrathin $\mathrm{MoS}_{2}$-based electrodes. The existence of surface negative charges on $\mathrm{MoS}_{2}$ discriminates or eliminates the interference of AA when it is present in excess while detecting the neurotransmitter DA. An extensive study on various redox probes with $\mathrm{MoS}_{2}$ indicates that $\mathrm{MoS}_{2}$ electrodes can be extended to the selective detection of other biomolecules. Further, it is demonstrated that the entire $\mathrm{MoS}_{2}$ surface is in a favorable geometry to accommodate enzymes; thereby, this opens up the possibility for highly sensitive enzymatic biosensing applications. This opens up the possibility for developing $\mathrm{MoS}_{2}$ nanosheet-based flexible biosensors for a point-of-care diagnosis.

\section{Acknowledgments}

TNN and SA acknowledge the financial support from CSIRCECRI in the form of institution start-up money (OLP 0087 and OLP 0088). Authors acknowledge Dr Sheela Berchmans, Chief Scientist, CSIR-CECRI and Dr Vijayamohanan K Pillai, Director, CSIR-CECRI for their support rendered during this work. The authors acknowledge Mr Rathish, CIF (Central Instrumentation Facility) of CSIR-CECRI, for his TEM measurements.

\section{References}

[1] Sivacarendran B, Sumeet W, Hussein N, Jian Z O, Serge Z, Richard B K, Sharath S, Madhu B and Kourosh K 2013 Adv. Funct. Mater. 23 3952-70

[2] Sheneve Z B et al 2013 ACS Nano 7 2898-926 
[3] Mingsheng X, Tao L, Minmin S and Hongzheng C 2013 Chem. Rev. 113 3766-98

[4] Kristie J K and Yi C 2013 ACS Nano 7 3739-43

[5] Yongjie Z, Zheng L, Sina N, Ajayan P M and Jun L 2012 Small 8 966-71

[6] Sina N, Zheng L, Wu Z, Xiaolong Z, Gang S, Sidong L, Boris I Y, Juan-Carlos I, Ajayan P M and Jun L 2013 Nat. Nanotech. 12 754-9

[7] Nardeep K, Sina N, Qiannan C, Frank C, Ajayan P M, Jun L and Hui Z 2013 Phys. Rev B 87 161403(R)

[8] Per J, Frint R F and Roy M S 1986 Mat. Res. Bull. 21 457-61

[9] Choi M S, Lee G H, Yu Y J, Lee D Y, Lee S H, Kim P, Hone J and Yoo W J 2013 Nat. Comm. 41624

[10] Hongsuk N, Sungjin W, Hossein R, Mikai C, Greg P, Wei L and Xiaogan L 2013 ACS Nano 7 5870-81

[11] Radisavljevic B, Radenovic A, Brivio J, Giacometti V and Kis A 2011 Nat. Nanotechnol 6 147-50

[12] Colleman J N et al 2011 Science 331 568-71

[13] Jaime T T, Narayanan T N, Guanhui G, Matthew R, Dmitri A T, Matteo P and Ajayan P M 2012 ACS Nano 6 1214-20

[14] Mark A L, Andrew S D, Fei M, Audrey F, Linsen Li and Song J 2013 J. Amer. Chem. Soc. 135 10274-7

[15] Lei L, Jie Z, Xiaojun B, Lina Z, Micheál D S, Hubert H G and Baohong L 2013 Adv. Funct. Mater. 23 5326-33

[16] Desheng K, Haotian W, Judy J C, Mauro P, Kristie J K, Jie Y and Yi C 2013 Nano Lett. 13 1341-7

[17] Venton B J and Wightman R M Anal. Chem. 75 414A-21A

[18] Robinson D L, Venton B J, Heien M L A V and Wightman R M 2003 Clinical Chem. 49 1763-73

[19] Hoglinger G U, Rizk P, Muriel M P, Duyckaerts C, Oertel W H, Caille I and Hirsch E C 2004 Nat. Neurosci. 7 726-35

[20] Hirsch A M and Graybiel Y A 1998 Nature 334 345-8

[21] Davis K L, Kahn R S, Ko G and Davidson M 1991 Am. J. Psychiatry 148 1474-86
[22] Singer H S, Szymanski S, Giuliano J, Yokoi F, Dogan A S, Brasic J R, Zhou Y, Grace A A and Wong D F 2002 Am. J. Psychiatry 159 1329-36

[23] Wightman R M 2006 Science 311 1570-4

[24] Kita J M and Wightman R M 2008 Cur. Opi. Chem. Biol. 12 491-6

[25] Deakin M R, Kovach P M, Stutts K J and Wightman R M 1986 Anal. Chem. 58 1474-80

[26] Zen J M and Chen I L 1997 Electroanal. 9 537-40

[27] Downard A J, Roddick A D and Bond A M 1995 Anal. Chim. Acta 317 303-10

[28] Zachek M K, Hermans A, Wightman R M and McCarty G S 2008 J. Electroanal. Chem. 614 113-20

[29] Alwarappan S, Liu C, Erdem A and Li C Z 2009 J. Phys. Chem C 113 8853-7

[30] Cao X, Ding Y, Zou X and Bian R 2008 Sensors Actuators B 129 941-6

[31] Malem F and Mandler D 1993 Anal. Chem. 65 37-41

[32] Alwarappan S, Butcher K S A and Wong D K Y 2007 Sensors Actuators B 128 299-305

[33] Shin D, Tryk D A, Fujishima A, Merkoçi A and Wang J 2005 Electroanal. 17 305-11

[34] Wang J 2008 Chem. Rev. 108 814-25

[35] Clark L Jr and Lyons C 1962 Ann. NY. Acad. Sci. 102 29-45

[36] Wang J 2002 Sensors Update 10 107-19

[37] Frew J and Hill H A 1987 Anal. Chem. 59 933A-9A

[38] Alwarappan S, Liu C, Kumar A and Li CZ 2010 J. Phys. Chem. C 114 12920-4

[39] Shao Y Y, Wang J, Wu H, Liu J, Aksay I A and Lin Y H 2010 Electroanalysis 22 1027-36

[40] Wu S, Zeng Z, He Q, Wang Z, Wang S J, Du Y, Yin Z, Sun X, Chen W and Zhang H 2012 Small 8 2264-70

[41] Bucur R V, Bartes A and Mecea V 1977 Electrochim. Acta. 23 641-6

[42] Chen P, Fryling M.A and McCreery R L 1995 Anal. Chem. 67 3115-22

[43] Gei F et al 2012 Chem. Commun. 48 6484-6

[44] http://2spi.com/catalog/molybdenum.shtml 